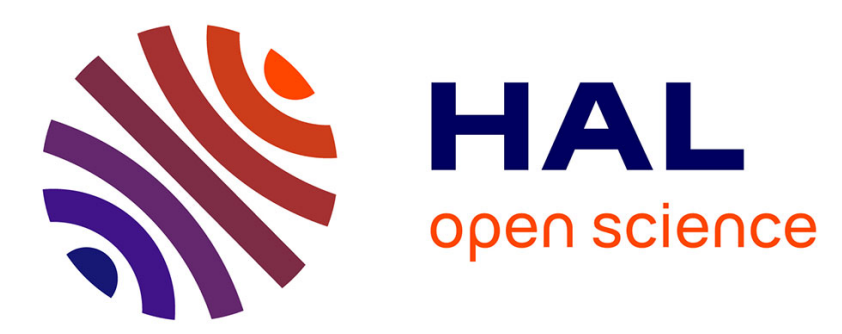

\title{
New architectured hybrid sol-gel coatings for wear and corrosion protection of low-carbon steel
}

Claire Lavollée, Marie Gressier, Julien Garcia, Jean-Michel Sobrino, Jean Reby, Marie-Joëlle Menu, Stefano Rossi, Michele Fedel

\section{To cite this version:}

Claire Lavollée, Marie Gressier, Julien Garcia, Jean-Michel Sobrino, Jean Reby, et al.. New architectured hybrid sol-gel coatings for wear and corrosion protection of low-carbon steel. Progress in Organic Coatings, 2016, 99, pp.337-345. 10.1016/j.porgcoat.2016.06.015 . hal-01473628

\section{HAL Id: hal-01473628 \\ https://hal.science/hal-01473628}

Submitted on 22 Feb 2017

HAL is a multi-disciplinary open access archive for the deposit and dissemination of scientific research documents, whether they are published or not. The documents may come from teaching and research institutions in France or abroad, or from public or private research centers.
L'archive ouverte pluridisciplinaire HAL, est destinée au dépôt et à la diffusion de documents scientifiques de niveau recherche, publiés ou non, émanant des établissements d'enseignement et de recherche français ou étrangers, des laboratoires publics ou privés. 


\section{OATAO \\ Open Archive Toulouse Archive Ouverte}

\section{Open Archive TOULOUSE Archive Ouverte (OATAO)}

OATAO is an open access repository that collects the work of Toulouse researchers and makes it freely available over the web where possible.

This is an author-deposited version published in : http://oatao.univ-toulouse.fr/ Eprints ID : 16642

To link to this article : DOI:10.1016/j.porgcoat.2016.06.015

URL : http://dx.doi.org/10.1016/j.porgcoat.2016.06.015

To cite this version : Lavollée, Claire and Gressier, Marie and Garcia, Julien and Sobrino, Jean-Michel and Reby, Jean and Menu, MarieJoëlle and Rossi, Stefano and Fedel, Michele New architectured hybrid sol-gel coatings for wear and corrosion protection of lowcarbon steel. (2016) Progress in Organic Coatings, vol. 99. pp. 337345. ISSN 0300-9440

Any correspondence concerning this service should be sent to the repository administrator: staff-oatao@listes-diff.inp-toulouse.fr 


\title{
New architectured hybrid sol-gel coatings for wear and corrosion protection of low-carbon steel
}

\author{
Lavollée Claire $^{\mathrm{a}, \mathrm{b}, *}$, Gressier Marie ${ }^{\mathrm{a}}$, Garcia Julien ${ }^{\mathrm{b}}$, Sobrino Jean-Michel ${ }^{\mathrm{b}}$, Reby Jean ${ }^{\mathrm{c}}$, \\ Menu Marie-Joëlle ${ }^{\mathrm{a}}$, Rossi Stefano ${ }^{\mathrm{d}}$, Fedel Michele ${ }^{\mathrm{d}}$ \\ a Université de Toulouse, Université Paul Sabatier, Institut Carnot CIRIMAT, 118 Route de Narbonne, 31062 Toulouse Cedex 09, France \\ b CETIM, Pôle "Matériaux Métalliques et Surfaces", 52 Avenue Félix Louat, CS 80067, 60304 Senlis Cedex, France \\ ' CETIM, Pôle "Matériaux Métalliques et Surfaces", 74 Route de la Jonelière, CS 50814, 44308 Nantes Cedex 3, France \\ d Department of Industrial Engineering, University of Trento, via Sommarive 9, 38123 Trento, Italy
}

Keywords:

Mild steel

Architectured coating

Sol-gel

Corrosion protection

Wear

Abrasion

\begin{abstract}
A B S T R A C T
The replacement of expensive stainless steel in various socio-economic sectors such as mechanical or alimentary is an issue that would be possible to solve by developing a protective coating on low-carbon steel. In these applications, complex pieces are in contact with different kinds of fluids, with or without particles when functioning. Consequently, the expected coating function is to effectively protect the equipment from corrosion, abrasion and erosion.

In this work thin hybrid coatings obtained by the sol-gel process have been developed for corrosion and wear protection on low-carbon steel. This innovative system is constituted of alumino-silicate epoxy based sol-gel coatings acting as barrier layers which, when loaded with zirconia particles, improve the mechanical properties. Taking into account the specificity of the carbon steel, we developed two architectured coatings displaying corrosion and wear protection. They are built by superposition of a bi-layered hybrid primer coating and a mono-layered zirconia loaded hybrid coating. Using two different zirconia contents, $30 \mathrm{wt} . \%$ and $40 \mathrm{wt} . \%$, thin coatings of 5 and $10 \mu \mathrm{m}$ are achieved. What is of interest is that the combination of antiwear tests and EIS to evaluate the influence of abrasive wear on anticorrosion properties has, for the first time, been demonstrated on such thin hybrid sol-gel coatings. The loss of corrosion protection of the lower zirconia loaded coating was attributed to the formation of localized defects after removal of material. On the contrary, the higher zirconia loaded coating demonstrated an interesting corrosion and wear behavior with the formation of a compacted layer at the top of the outer layer providing a barrier effect against water and ion permeation. To further characterize the protective systems, the morphology and the microstructure of the coatings were investigated by scanning electron microscopy.
\end{abstract}

\section{Introduction}

Various protection systems are used for corrosion protection of mild steel. The use of organic coatings is one of the most common methods for corrosion protection of industrial components. According to the way they are applied, paints can cause environmental problems. This is the case of liquid paints containing volatile organic compounds the thickness of which range from 140 to $600 \mu \mathrm{m}$ depending on the corrosion requirements. Water-based paints are also developed but still contain a residual of solvent.

\footnotetext{
* Corresponding author at: Université de Toulouse, Université Paul Sabatier, Institut Carnot CIRIMAT, 118 Route de Narbonne, 31062, Toulouse Cedex 09, France. E-mail address: lavollee@chimie.ups-tlse.fr (L. Claire).
}

To overcome environmental concerns, a powder coating process is used in the industry to coat and protect metal surfaces. The most commonly thermosetting resin powders used are polyesters, epoxy, epoxy polyesters [1-3]. These coatings are applied in one layer $(60-80 \mu \mathrm{m})$ or two layers $(160-200 \mu \mathrm{m})$ depending on the exposure conditions and the required durability. Recently, Montemor [4] described, in a review, different functional coatings and especially siloxane-modified epoxy coatings deposited on steel [5-7] which significantly improve conventional epoxy coatings properties. Another process used in industrial sectors is a protective thin layer electrodeposited [8] (15-25 $\mu \mathrm{m})$, but despite good corrosion resistance to salt spray test, additives present in the baths such as co-solvents and heavy metals can cause environmental problems. 
These protective systems present high thicknesses or even show limitations such as the presence of co-solvents, heavy metals or volatile organic compounds. A suitable technique to combine hard and pliant materials is the sol-gel process, where the hydrolysis and condensation reactions of inorganic alkoxides provide an inorganic network after appropriate thermal treatment. When organosilanes are involved in the process, a highly cross-linked network containing organic and inorganic parts is formed. These materials are of interest because they combine both properties of the organic polymer and the inorganic materials. The hardness and the flexibility of the coating can be adjusted by the amount of inorganic compounds (alumina, silica...) as well as polymerizable groups (e.g. epoxy, vinyl, methacrylate) for the formation of a dense network. Moreover the chemical compatibility with organic paints facilitates the adhesion of the coating to the substrate and the introduction of corrosion inhibitors such as cerium(III) salts improves coating performances against corrosion $[9,10]$. Finally, the hardness and mechanical resistance of the organic-inorganic hybrid coatings can be increased by nanoparticle reinforcement. Among the well-described coatings containing oxide nanoparticles which are essentially deposited on aluminum alloys, some papers deal with coated steel relating to different nanoparticles e.g. Zn [11], Montmorillonite [12], $\mathrm{Al}_{2} \mathrm{O}_{3}$ [13,14], $\mathrm{ZrO}_{2}$ [15,16], $\mathrm{SiO}_{2}$ [14,15,17,18] distributed in the hybrid matrix. The introduction of the nanoparticles within the hybrid sol may be done either as nanoscale powder [15], synthesized in-situ [16] or colloidal suspension [18].

The performance of a coating in an abrasion test depends on the intrinsic properties of the coating material as well as the film thickness and the adhesion of the sol-gel coating to the substrate. For example, the optimal amount of particles incorporated in the coatings clearly depends on its sol-gel matrix. This is highlighted by Grundwürmer et al. [19] who demonstrated that the addition of zirconia nanoparticles could either have a positive or negative effect on the erosion performances. Wilkes et al. [20]. explained that sol-gel coatings applied on various substrates, e.g. copper, brass and stainless steel are effective in wear control but have a poorer performance on the plain steel, due to a lower level of adhesion to the substrate.

The aimed protective coatings require good resistance to corrosion and abrasion. Indeed, mechanical damage can locally result in the reduction of the protective properties of a coating and, thus, a corrosion attack of the substrate might occur. Hence, the necessity to evaluate the resistance to the abrasion of the coating systems is achieved by abrasive wear tests. These tests have limitations in so far as they do not determine a precise value of the protective capacity, but they do allow the performance of comparative tests among the different coating systems. The most interesting abrasive wear test on coating is the Taber test [21], initially developed to evaluate the resistance of thick organic layers [1-3], and less applied to other sol-gel coated systems $[16,20]$.

Wear and corrosion properties are usually independently investigated so that the influence of mechanical degradation on corrosion coatings performance is not well-correlated. During mechanical damage action, and taking thickness decrease and mass loss into consideration, as indicated in the standard, insufficient information can be extrapolated about the damage of the coating and its residual protective properties. In this sense, a test procedure has been developed to evaluate the decrease of protective properties by means of electrochemical impedance spectroscopy (EIS), after Taber Abraser standard test [1].

To date, particle-reinforced hybrid sol-gel coatings on corroding materials such as carbon steels have been poorly developed. One of the strategic issues of this technology is how the sol-gel can be formulated to obtain both high corrosion and abrasion resistant coatings on mild steel. This system should combine the barrier pro-
Table 1

Chemical composition of low-carbon steel (Fe balance).

\begin{tabular}{llllll}
\hline Element & $\mathrm{C}$ & $\mathrm{Mn}$ & $\mathrm{Ni}$ & $\mathrm{Cr}$ & Mo \\
\hline Mass\% & 0.047 & 0.26 & 0.010 & 0.016 & $\leq 0.005$ \\
\hline
\end{tabular}

tection effect of hybrid silicated and cerium doped coatings with the reinforcing action of nanoparticles.

The aim of this work was to design two innovative architectured systems combining bi- and monolayer coatings, the outer layer of which contains zirconia nanoparticles. Abrasion degradation of the architectured organic-inorganic sol-gel coatings caused by Taber Abraser was evaluated. Electrochemical impedance measurements and microstructural analysis were undertaken to evaluate the performance of the protecting systems. The two architectured systems have been compared and the best anticorrosive performances of such sol-gel coatings have been highlighted.

\section{Experimental procedure}

\subsection{Sample preparation}

The metal substrates are panels of low-carbon steel $100 \mathrm{~mm} \times 100 \mathrm{~mm} \times 1 \mathrm{~mm}$ the composition of which is given in Table 1. The metal substrates, after surface cleaning with acetone, were pre-treated following these two steps: 5 min immersion in $\mathrm{NaOH}, 1.125 \mathrm{~mol} \mathrm{~L}^{-1}$ alkaline degreasing solution maintained at $60^{\circ} \mathrm{C}$ to remove all traces of oil following by $5 \mathrm{~min}$ immersion in hydrochloric acid $\left(5.5 \mathrm{~mol} \mathrm{~L}^{-1}\right)$ at room temperature in order to remove oxides or compounds on the surface of the sample and improve wettability. Samples are finally washed in ethanol and dried in air.

\subsection{Sol and coating preparation}

Glycidoxypropyltrimethoxysilane (GPTMS), aluminum isopropoxide (AIP, $\geq 98 \%$ ) and cerium nitrate hexahydrate (Ce $\left.\left(\mathrm{NO}_{3}\right)_{3}, 6 \mathrm{H}_{2} \mathrm{O}\right)$ are obtained from Aldrich, polyethylene glycol PEG 35000 is obtained from Fluka, zirconia nanoparticles (TOSOH, $40 \mathrm{~nm}$ ) were purchased from IMCD. The size of the TOSOH nanoparticles has been controlled by FEG-SEM observation. Zirconia nanoparticles were suspended in a 1:25 v:v water: isopropanol mixture. All others reagents were used as received.

SO sol formulation of the primer layer was prepared by mixing GPTMS (5.94 g, $0.0251 \mathrm{~mol})$ and AIP $(3.6 \mathrm{~g}, 0.0176 \mathrm{~mol})$ in a molar ratio of 1.7 , in isopropanol $11.25 \mathrm{~mL}(0.1479 \mathrm{~mol})$. Cerium nitrate hexahydrate $(1.00 \mathrm{~g}, 0.0023 \mathrm{~mol})$ was dissolved in distilled water (25.8 $\mathrm{g}, 1.43 \mathrm{~mol}$ ) and then added to the previous mixture. The sol was prepared for a final volume of $46.1 \mathrm{~mL}$. It was maturated during $24 \mathrm{~h}$ at room temperature. After maturation, the viscosity of the S0 formulation is 7 mPa.s.

For the S1 and S2 zirconia nanoparticles loaded sols, first GPTMS $(9.52 \mathrm{~g}, 0.0403 \mathrm{~mol})$ and AIP $(2.4 \mathrm{~g}, 0.0118 \mathrm{~mol}))$ in a molar ratio of 3.4 , are mixed in isopropanol $7.5 \mathrm{~mL}(0.0986 \mathrm{~mol})$. Aqueous solution of cerium nitrate hexahydrate $(0.67 \mathrm{~g}, 0.0015 \mathrm{~mol}$ in $6 \mathrm{~g}, 0.33 \mathrm{~mol}$ of water, $0.05 \mathrm{~mol} \mathrm{~L}^{-1}$ ) was added to the sol which is vigorously stirred. Then PEG $35000(0.61 \mathrm{~g})$ diluted in distilled water $6 \mathrm{~mL}$ ) at a final concentration of $20 \mathrm{~g} \mathrm{~L}^{-1}$ was added to the sol. The sol was maturated during $24 \mathrm{~h}$ at room temperature and then $\mathrm{X} \mathrm{mL}$ of sol was introduced in the zirconia suspensions containing 13.6 or $20.7 \mathrm{~g}$ in $25.9 \mathrm{~mL}$ of $1: 25 \mathrm{v}: \mathrm{v}$ water:isopropanol to give S1 and S2 sols containing $30 \mathrm{wt} . \%$ and $40 \mathrm{wt} . \%$ of $\mathrm{ZrO}_{2}$ nanoparticles, respectively. After maturation, the viscosity of the $\mathrm{S} 1$ and $\mathrm{S} 2$ formulations reaches 12 and $18 \mathrm{mPa}$.s respectively.

Two architectured coatings were produced by a dip-coating procedure at a controlled withdrawal rate of $20 \mathrm{~cm} \mathrm{~min}^{-1}$. They were 


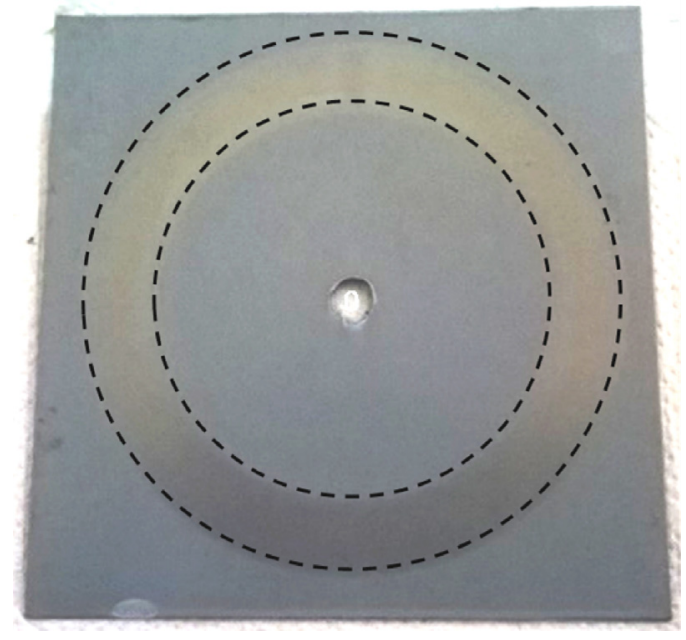

Fig. 1. C1 coating after 1000 cycles abrasion test.

composed of a bi-layers coating using S0 sol, and a zirconia loaded mono-layer coating involving S1 (30 wt.\%) and S2 (40wt.\%) sols respectively, to provide $\mathrm{C} 1$ and $\mathrm{C} 2$ architectured coatings. To elaborate these multi-layered systems, the coating was dried after each dip $1 \mathrm{~h}$ at $50^{\circ} \mathrm{C}$ then the final heat treatment was processed $50^{\circ} \mathrm{C}$ for $30 \mathrm{~min}$ and $150^{\circ} \mathrm{C}$ for $4 \mathrm{~h}$.

\subsection{Characterization of the sols and the coatings}

The viscosity of the sols were measured with a Rheomat RM100 rheometer for shearing rates ranging between 644 and $966 \mathrm{~s}^{-1}$. The thermal analysis of the sols and the xerogels were performed using the device SETARAM (TG-DTA92). Microstructural properties and coatings thickness were observed by scanning electron microscopy (SEM) with a JEOL JSM-6400 SEM instrument, by using an environmental scanning electron microscope TMP ESEM FEI (ESEM Philips XL30) and by a JEOL JSM-6700F-EDS FEG-SEM. The abrasion tests were carried out with a Taber Abraser 5135 using abrasive wheels called CS10 wheels (small abrasive particles, which simulates the effect of polishing or cleaning), an applied load of $250 \mathrm{~g}$; the entire test consisted of 1000 cycles [18]. During the abrasion testing, the wheels were refaced after every step abrasion cycles. The electrochemical set-up exploited to carry out the EIS measurements consisted in a "mobile cell" [3] allowed to investigate the electrochemical response of the protection system after each abrasion step.

The "mobile cell" consists in two concentric PVC cylinders which are designed to delimitate the Taber track. The cylinders are not glued to the surface of the metal but are pressed to on it by means of four screws connected to an external framework. The edge of the cylinders in contact with the metal are coated with a silicon gasket to prevent the electrolyte spread. After each EIS measurement, the cell was removed and the sample underwent a new abrasion step. The tested area (about $37.5 \mathrm{~cm}^{2}$ ) included the whole abraded area which consists of an approximately $1 \mathrm{~cm}$ thick ring, indicated Fig. 1 by the dotted line.

To avoid the influence of possible water uptake, after every EIS test the sample was treated for $10 \mathrm{~min}$ at $45^{\circ} \mathrm{C}$ to induce water evaporation and cooled $10 \mathrm{~min}$ at room temperature. EIS measurements were carried out at the initial step ( 0 cycle) and after 100 and 1000 cycles using a PAR 273 potentiostat and a Solartron 1255 frequency response analyzer in the frequency range between $100 \mathrm{kHz}$ and $10 \mathrm{mHz}$, with a $20 \mathrm{mV}$ amplitude signal, at the free corrosion potential. A counter electrode of platinum and a reference electrode of $\mathrm{Ag} / \mathrm{AgCl}$ (+207 $\mathrm{mV}$ vs SHE) were used. The electrolyte was a 0.3 wt.\% $\mathrm{Na}_{2} \mathrm{SO}_{4}$ solution. Such a mild medium has been employed as the aim is to investigate the abrasion resistance of the coatings. For this purpose, EIS has been exploited in order to monitor the decrease of protection properties of the coatings promoted only by the mechanical action of the abrasive wheels. In this sense, the use of aggressive sodium chloride contain media would lead to an "additional" extent of degradation not related to wear process. ZSimpwin software was employed for the numerical fitting of the experimental spectra.

Each experiment was realized in triplicate and was repeatable.

\section{Results and discussion}

\subsection{Architectured coatings}

Architectured systems investigated in this study are built by superposition of a bi-layered hybrid primer coating and monolayered zirconia loaded hybrid coating. As recently reported, anticorrosion protections of steel substrates are obtained from an organic-inorganic hybrid, most often involving tetraethoxysilane (TEOS) associated with 3-methacryloxypropyltriethoxysilane (MAP) or methyltriethoxysilane (MTES) and rarely with 3glycidoxypropyltrimethoxysilane (GPTMS) [22] . Mechanical properties are improved when aluminium alkoxide [23] or zirconia nanoparticles [15] are introduced in the formulation. In our work the sol formulations were based on glycidoxypropyltrimethoxysilane (GPTMS) and aluminum iso-propoxide (AIP) in isopropanol. Cerium nitrate in aqueous solution was introduced as an inorganic corrosion inhibitor [24,25]. As studied in our previous work [27] involving GPTMS-AIP formulations, improved corrosion properties were observed when the $\mathrm{Si} / \mathrm{Al}$ ratio was in the range 1 and 2 so a $\mathrm{Si} / \mathrm{Al}$ ratio equal to 1.7 has been used for the bi-layered primer coating. S0 sol formulated from these three compounds was maturated $24 \mathrm{~h}$ at room temperature. Dip-coating procedure of two S0 sol deposits on mild steel substrate was followed by a thermal treatment giving a bi-layered hybrid primer coating.

In order to obtain thicker deposits, S0 formulation was investigated giving S1 and S2 sols which will constitute, after deposition, the outer mono-layer. The $\mathrm{Si} / \mathrm{Al}$ ratio was chosen equal to 3.4 to increase the organic part, PEG 35000 was incorporated as a plasticizer to increase the viscosity [26] and zirconia particles were added to provide a reinforcement of corrosion and mechanical properties. S1 and S2 formulations contain $30 \mathrm{wt} . \%$ and $40 \mathrm{wt} . \%$ of $\mathrm{ZrO}_{2}$ nanoparticles respect to the total sol, respectively. Before deposition sols were maturated $24 \mathrm{~h}$ at room temperature. The heat treatment has been determined by thermal analysis of the xerogels which shows two main trends (see Supplementary material, Fig. 1). The presence of a stable and densified material up to $250^{\circ} \mathrm{C}$ and the slow degradation of organic matter from $250^{\circ} \mathrm{C}$ to $600^{\circ} \mathrm{C}$. Therefore, in order to preserve the organic part of the architectured coating, it was dried at $50^{\circ} \mathrm{C}$ for $30 \mathrm{~min}$ and then treated at $150{ }^{\circ} \mathrm{C}$ for $4 \mathrm{~h}$.

Considering the surface roughness of the mild steel in the range $0.8-1 \mu \mathrm{m}$ after cleaning and the low sol viscosity of S0 formulation around $7 \mathrm{mPa}$, the primer was deposited as a bi-layered the thickness of which reaches a maximum of $4 \mu \mathrm{m}$, depending on the surface roughness. This primer coating is homogeneous, crack-free, covering and leveling the substrate. The thickness of the outer layer varies from 2 to $3 \mu \mathrm{m}$ to $8 \mu \mathrm{m}$ in agreement with the different contents of zirconia nanoparticles, the higher the amount of particles in the sol, the thicker the coating. This is well illustrated by electron micrographs of the cross-section of the two undamaged systems, reported in Fig. 2, where the thickness of the total architectured systems reachs $5 \mu \mathrm{m}$ and $10 \mu \mathrm{m}$ for $\mathrm{C} 1$ and $\mathrm{C} 2$ respectively. Both samples exhibit a nanocomposite outer layer constituted of zirco- 
a

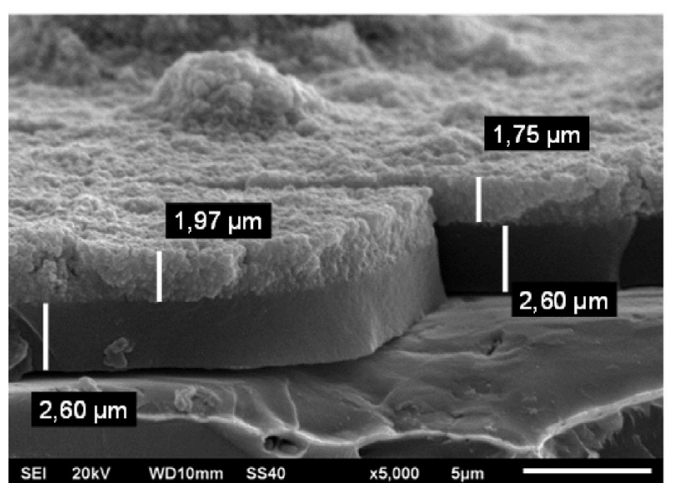

b

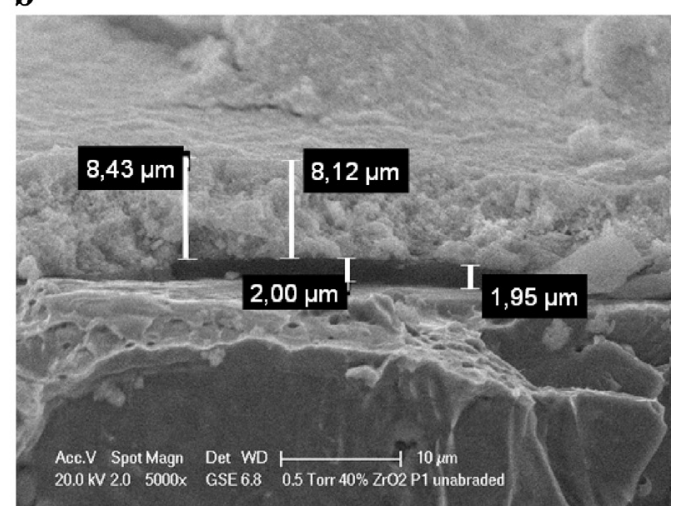

Fig. 2. (a) SEM image of the $C 1$ architectured system and (b) ESEM image of the $C 2$ architectured systems before abrasion cycles.

nia nanoparticles embedded in alumino-silicated matrix with some aggregates of nanoparticles (Fig. 2a and b).

Architecture of the $\mathrm{C} 1$ and $\mathrm{C} 2$ coatings is well highlighted in these images with the difference in contrast between the mostly hybrid part of the primer coating and the zirconia part of the loaded layer. For both C1 and C2 coatings, an extremely good cohesion of both layers, hybrid and loaded, is demonstrated here taking into consideration that these images are obtained by liquid nitrogen brittle fracture method for the preparation of the samples for SEM and ESEM observations.

\subsection{Influence of the $\mathrm{ZrO}_{2}$ content on the morphology damage}

In this section, the Taber tests results are described for the two zirconia contents loaded coatings with an imposed weight of $250 \mathrm{~g}$ and CS10 abrasive wheels. The thickness was measured in correspondence to the abrasion track after 100 and 1000 cycles together with the observation of the morphology of the damaged areas. Fig. 3 shows the electron micrographs of the cross-section of the coatings as liquid nitrogen brittle fracture. Comparing the evolution of the thickness of both coatings, $\mathrm{C} 1$ and $\mathrm{C} 2$ coatings did not exhibit the same behavior toward the applied Taber test. Concerning the C1 coating, one can see a very slight decrease of the coating thickness after 100 abrasion cycles (Fig. 3a) and even after 1000 abrasion cycles (Fig. 3b) where the thickness still remains around $5 \mu \mathrm{m}$. The $\mathrm{C} 2$ coating behavior is different since the thickness decreases from $10 \mu \mathrm{m}$ to $8 \mu \mathrm{m}$ after 100 cycles until $5 \mu \mathrm{m}$ after 1000 abrasion cycles (Fig. 3d and e) depending on the area position in the track.

Surprisingly, these abrasion conditions are severe enough to induce serious mechanical damage but not enough to remove the coating. However, advanced microscopic investigations of the cross section of the abraded surfaces after 1000 abrasion cycles reveal that both coatings are damaged, but deeper defects are detected in the lower zirconia loaded coating. A total removal of the outer layer is observed in some areas for C1 coating as illustrated in right side of this micrograph (Fig. 3c) where only the non-damaged primer coating is preserved with $2 \mu \mathrm{m}$ thickness. On the contrary only compaction of the outer mono-layer is observed for the thicker C2 coating (Fig. 3e). To complete microscopic characterization, the surface of the damaged coating was investigated. Fig. 4 shows SEM images of the damaged surfaces after the abrasion test. Decreasing the zirconia content leads to the formation of localized defects in the shape of punctual defects (Fig. 4a). A higher magnification of the image corresponding to the $\mathrm{C} 1$ coating abraded surface shows the removal of the outer layer (Fig. $4 \mathrm{~b}$ ) providing bare primer coating. Evidence of the preservation of the hybrid primer on the metallic substrate is demonstrated by the absence of the substrate topography. The C2 coating presents another morphology of damage
(Fig. 4d) with an heterogeneous surface highlighted by the different contrast areas when observing in secondary electron mode. High relief, which appears clearer in the micrograph, is attributed to a higher coating thickness, whereas low relief, which appears darker in the micrograph, is attributed to a lower coating thickness. To better characterize these two contrasted areas, FEG-SEM observations have been undertaken in both relevant areas in the track, indicated by the red square (Fig. 4e). As already observed in the micrograph of the cross section, the presence of zirconia nanoparticles in the lower thickness area was confirmed at higher magnification (Fig. 4f). The same conclusion was reached after observation of the clearest area (see Supplementary material, Fig. 3).

It is worth noting that during abrasion testing, the C2 coating is compressed under the action of the load and a compacted layer is formed. Fig. 5a clearly shows the presence of a compacted layer at the extreme surface following the abrasion cycles as evidence of the mechanical action of the abrasive wheels. SEM microscopy obtained by back-scattered electron detection mode (Fig. 5b) allowed us to estimate the compaction thickness of about $2 \mu \mathrm{m}$ of the outer layer.

The effect of zirconia loading shows a clear dependency on damage levels of the coatings during abrasion cycles. Given the experimental data, it is possible to conclude that depending on the anti-wear protective system, abrasive particles of the wheel will have different actions. They will either produce a series of localized defects with thinner coatings, or allow the formation of a compact and protective outer layer by mechanical abrasion.

\subsection{Influence of the $\mathrm{ZrO}_{2}$ content on the corrosion behavior}

The electrochemical properties of the coating were evaluated from the beginning of the test and at intermediate stages. This was done in order to follow the progressive mechanical damage to the same sample and to avoid the initial differences. Because the aim of this experiment is not to simulate a real corrosive environment but to evaluate the loss of protection properties due to the abrasion action of the abrasive wheels, a moderately corrosive electrolyte (i.e. $0.3 \mathrm{wt} \% \mathrm{Na}_{2} \mathrm{SO}_{4}$ ) was chosen [28]. A removable electrochemical cell was used in order to allow, once the measurement had been made, to continue with the abrasion test. Measurements were repeated three times and the repeatability was considered satisfactory. To obtain a better description of the damage process, EIS spectra were acquired at the initial step, after 100 and 1000 cycles. Fig. 6 shows the impedance diagrams of the non-abraded and abraded samples after 100 and 1000 cycles of abrasion using CS10 wheels and an imposed load of $250 \mathrm{~g}$. A bare steel plate (same composition of the coated samples) was investigated for comparison, in order to provide a reference of the behavior of the metal in 
a

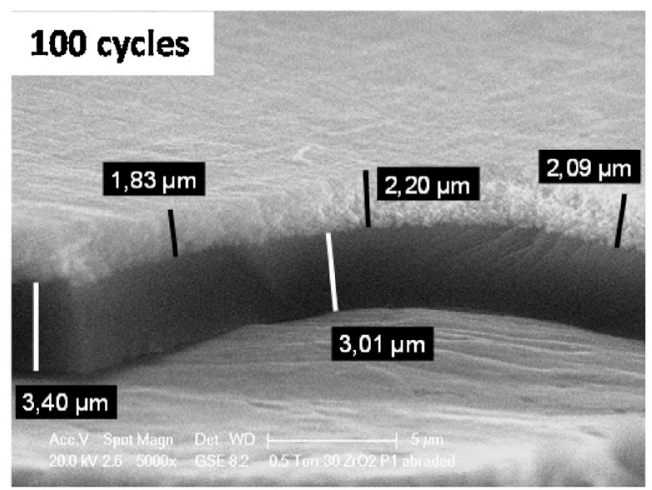

b

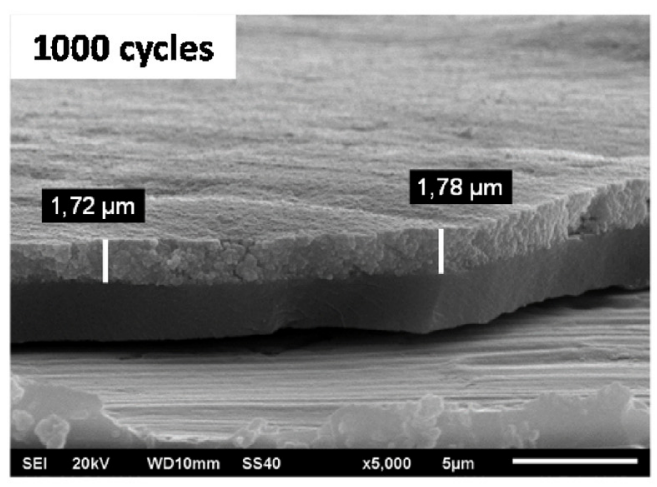

c

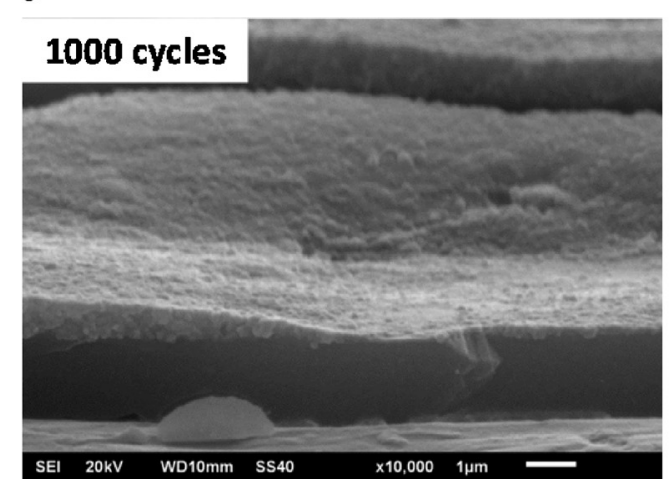

\section{d}

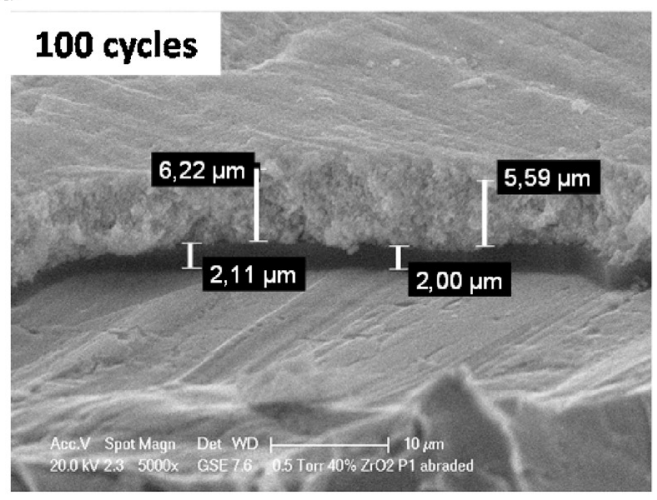

$\mathbf{e}$

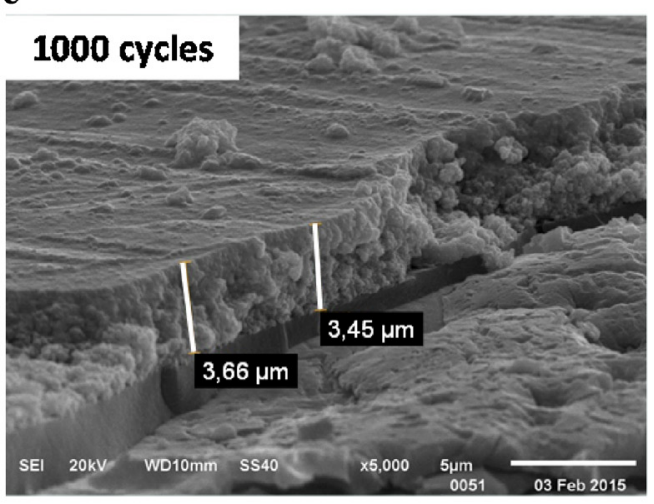

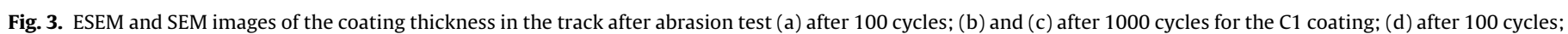
(e) after 1000 cycles for the C2 coating.

the employed electrolyte. Notice that the ohmic drop due to electrolyte resistivity is around $1 \mathrm{k} \Omega \times \mathrm{cm}^{2}$. Considering the relatively high impedance of the coatings, the ohmic drop is expected not to remarkably affect the experimental results. However, as far as the bare metal is concerned, the electrolyte resistivity affects the impedance spectrum which shows an almost resistive behavior in the high and middle frequency range.

The EIS spectra of the investigated samples, C1 (green dot) and C2 (red triangle), look similar before abrasion testing (Fig. 6). The values of the impedance modulus in the low frequency range $(0.01 \mathrm{~Hz})$ are about $10^{6} \Omega \mathrm{cm}^{2}$ and $10^{7} \Omega \mathrm{cm}^{2}$ for the $40 \mathrm{ZrO}_{2}$ and $30 \mathrm{ZrO}_{2}$ monolayer, respectively. Notice that the total impedance for the thinner coating (C1) is about one order of magnitude higher compared to the thicker one (C2). This fact can be related to a higher amount of defects in the $10 \mu \mathrm{m}$ thick coating compared to the $5 \mu \mathrm{m}$ thick one.

In any case, the low frequency impedance values for both coatings are significantly higher than the bare steel substrate (black square), whose impedance modulus reaches about of $10^{3} \Omega \mathrm{cm}^{2}$. At 0 cycle, the low-frequency impedance is related to the global protection properties of the system. It is believed that, after the very few minutes of immersion the low frequency impedance values of $10^{6} \Omega \mathrm{cm}^{2}$ and $10^{7} \Omega \mathrm{cm}^{2}$ depend mainly on the coating pore resistance. The measured impedance values for samples C1 and C2 are in agreement with those reported in literature [29] and show that the coatings have a good barrier property toward the electrolyte penetration.

With the expectation that the impedance modulus values would increase with the global thickness, the initial impedance modulus values seem to be more dependent on the microstructure of the coated systems and to the presence and extent of defects.

Even if the comparison of the pore resistance to those observed in literature is difficult, since it depends on the film thickness, the electrolyte used and the immersion time in the corrosive solution, the initial values of both coatings can be considered indicative of their protective properties. 
a

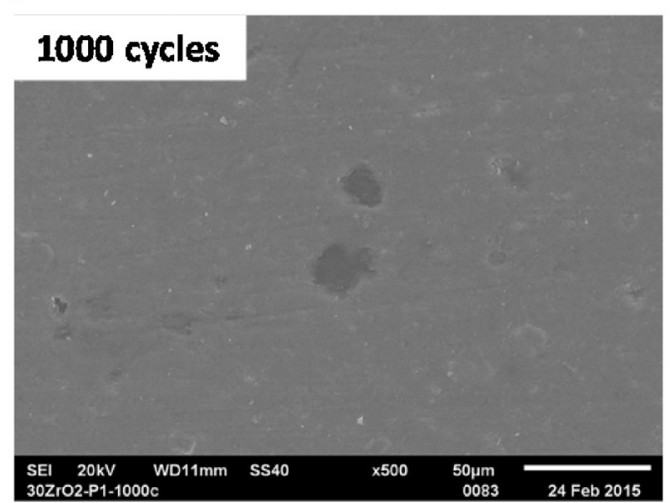

b

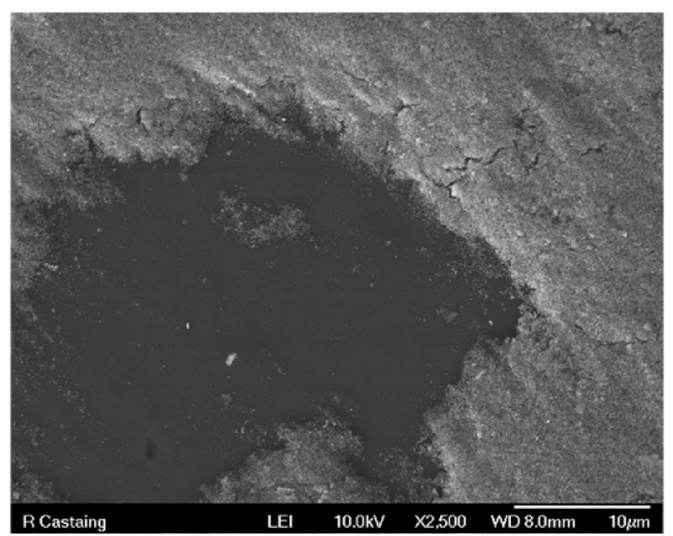

c

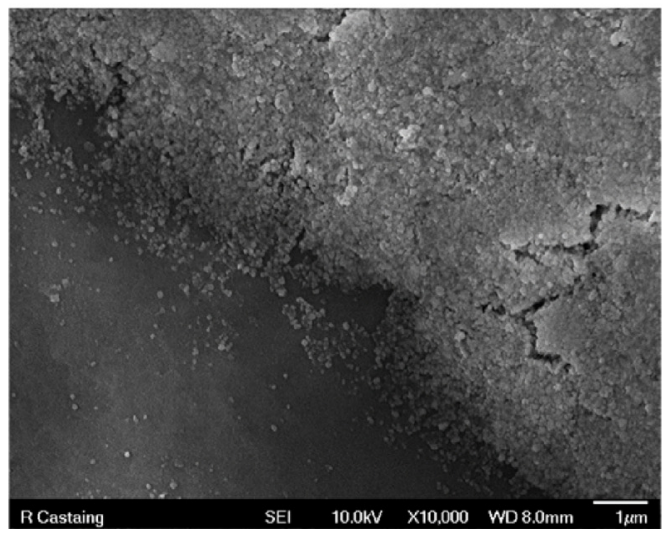

d

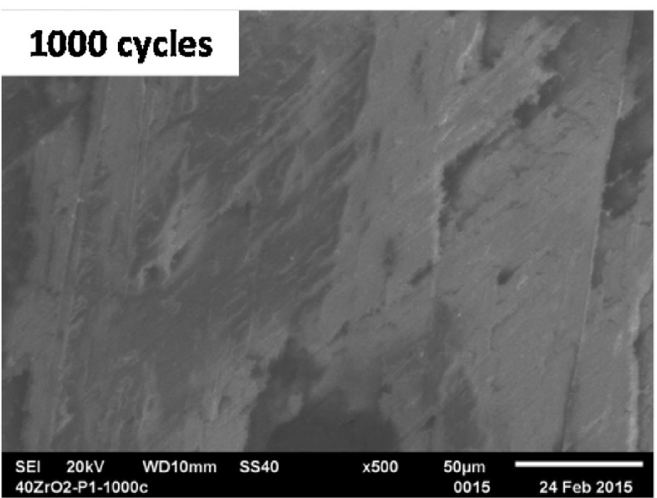

e

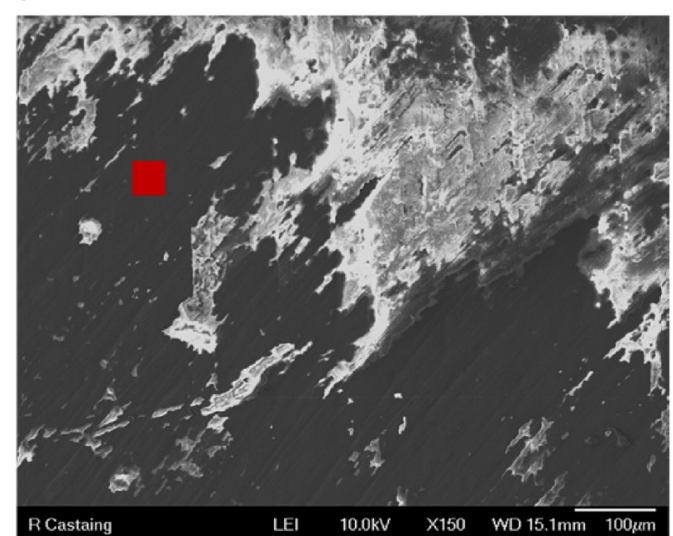

f

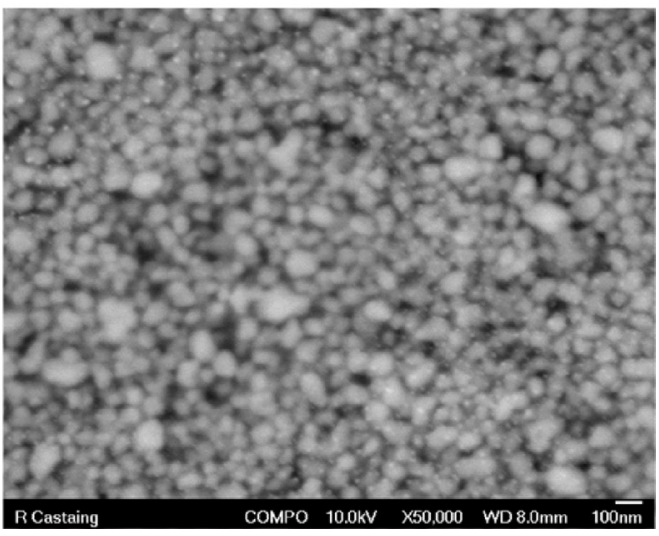

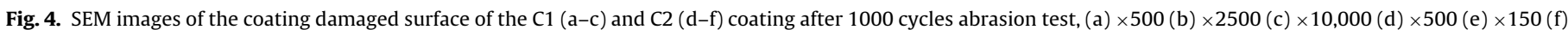
$\times 50,000$ in the darker area.

However, to better investigate the properties on the coatings before the Taber test, the impedance spectra collected over $\mathrm{C} 1$ and $\mathrm{C} 2$ samples were investigated by numerical fitting. From Fig. 7 it is possible to observe that three relaxation processes are present for both samples. The first, located in the $10^{5} \div 10^{2} \mathrm{~Hz}$ frequency range, is partially overlapped to the second one, observed in the $10^{2} \div 10^{0} \mathrm{~Hz}$ frequency range. The last relaxation process is present in the low frequency domain, below $10^{-1} \mathrm{~Hz}$.

According to literature [30], the circuit depicted in Fig. 8 has been exploited to fit the experimental data. The first resistance (namely $\mathrm{R}_{\mathrm{e}}$ ) stands for the electrolyte resistance. The high frequency time constant (modelled using a resistance, $\mathrm{R}_{\mathrm{HF}}$, and a constant phase element, $\mathrm{Q}_{\mathrm{HF}}$ ) has been attributed to the sol-gel coating. In particular, $\mathrm{R}_{\mathrm{HF}}$ is believed to represent the pore resistance attribute to the hybrid coating, while $\mathrm{Q}_{\mathrm{HF}}$ its dielectric response. The middle and low frequency time constants have been modelled using resistance and constant phase elements in parallel (namely $\mathrm{R}_{\mathrm{MF}} \mathrm{Q}_{\mathrm{MF}}$ and $\mathrm{R}_{\mathrm{LF}} \mathrm{Q}_{\mathrm{LF}}$, respectively). The low frequency time constant is expected to be related to the faradic process occurring at the metal substrate. Therefore, $\mathrm{R}_{\mathrm{LF}}$ can be considered as a charge transfer resistance, while $\mathrm{Q}_{\mathrm{LF}}$ a constant phase element related to the double layer capacitance. On the other hand the physical meaning of the relaxation process occurring in middle frequency range and modelled using $\mathrm{R}_{\mathrm{MF}}$ and $\mathrm{Q}_{\mathrm{MF}}$ connected in parallel, is not clear. It can be related to primer coating and/or to the corrosion products accumulating at the metal/solution interface.

Table 2 shows the results of the numerical fitting data for samples $C 1$ and C2 (electrolyte resistance, $R_{E}$, equal to $1.04 \mathrm{k} \Omega \mathrm{cm}^{2}$ in both cases). Notice that, according to the appearance of the spectra in Fig. 7 , the pore resistance $\left(R_{H F}\right)$ attributed to the sol-gel coat- 
a

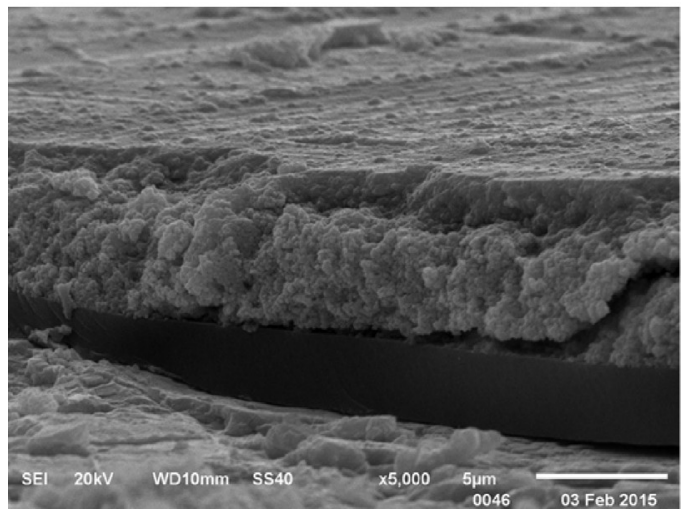

b

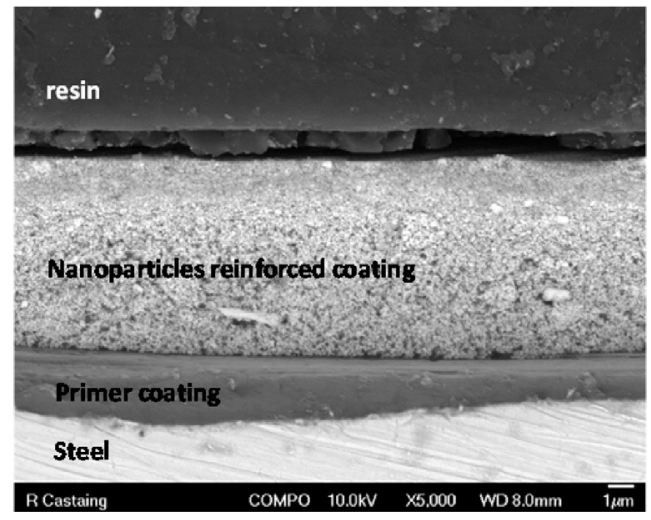

Fig. 5. SEM micrographs of the $\mathrm{C} 2$ coating after 1000 abrasion cycles test (a) fractured sample, (b) polished cross section.

0 Cycle
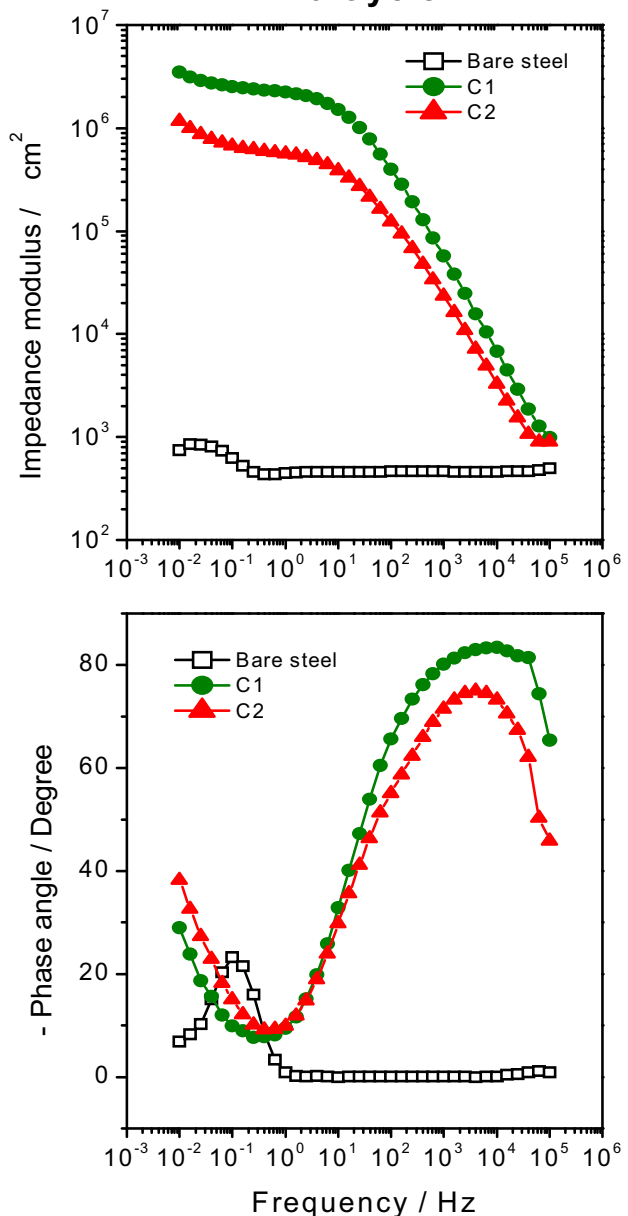

100 Cycles
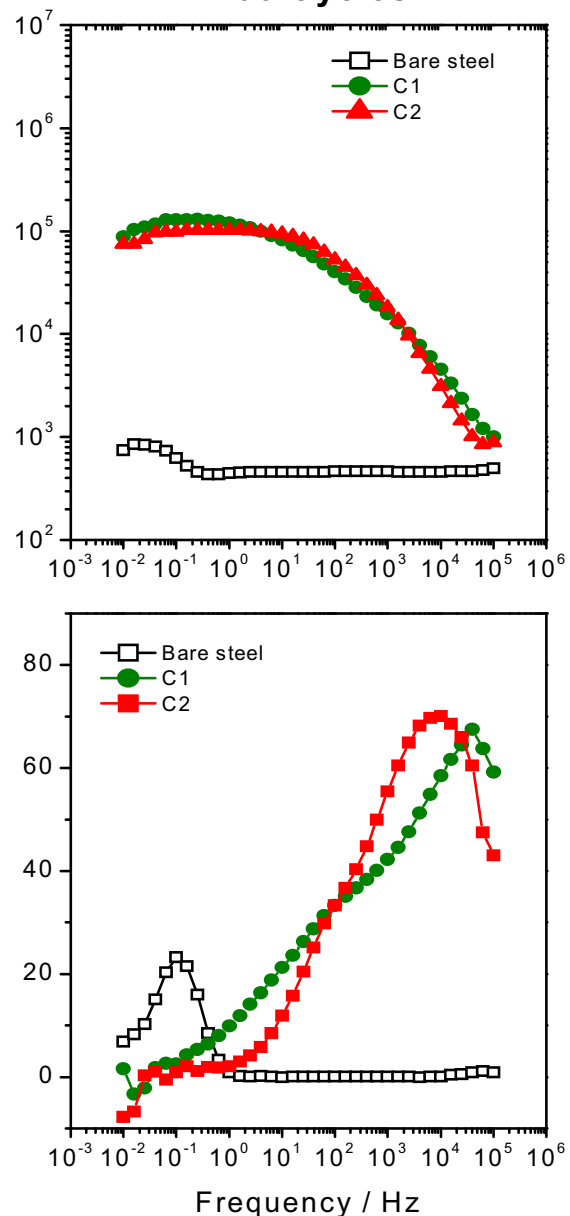

1000 Cycles
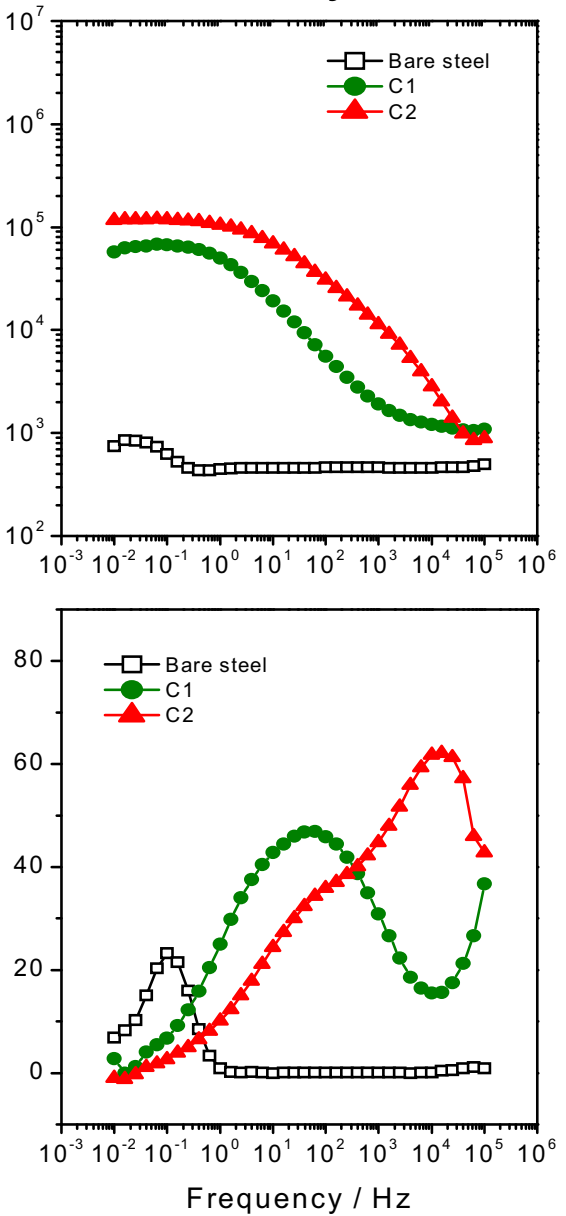

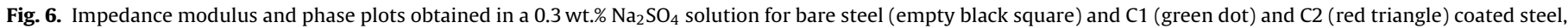

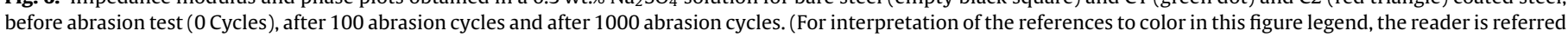
to the web version of this article.)

Table 2

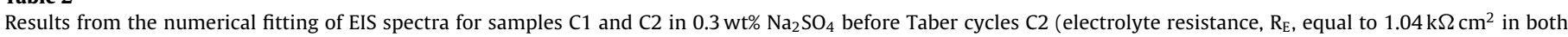
cases).

\begin{tabular}{|c|c|c|c|c|c|c|c|c|c|}
\hline & $\mathrm{R}_{\mathrm{HF}}\left(\Omega \mathrm{cm}^{2}\right)$ & $\begin{array}{l}\text { Pre-factor } Q_{H F} \\
\left(\mathrm{~S} \mathrm{~s} \alpha \mathrm{cm}^{-2}\right)\end{array}$ & Exponent $_{\alpha \mathrm{HF}}$ & $\mathrm{R}_{\mathrm{MF}}\left(\Omega \mathrm{cm}^{2}\right)$ & $\begin{array}{l}\text { Pre-factor } Q_{M F} \\
\left(\mathrm{~S} \mathrm{~s} \alpha \mathrm{cm}^{-2}\right)\end{array}$ & Exponent $_{\alpha \mathrm{MF}}$ & $\mathrm{R}_{\mathrm{LF}}\left(\Omega \mathrm{cm}^{2}\right)$ & $\begin{array}{l}\text { Pre-factor } Q_{\mathrm{LF}} \\
\left(\mathrm{S} \mathrm{s} \alpha \mathrm{cm}^{-2}\right)\end{array}$ & Exponent $_{\alpha \mathrm{LF}}$ \\
\hline $\mathrm{C} 1$ & $4.6410^{5}$ & $4.5310^{-9}$ & 0.94 & $1.9710^{6}$ & $2.8210^{-8}$ & 0.56 & $1.43 \times 10^{9}$ & $4.0310^{-6}$ & 0.74 \\
\hline $\mathrm{C} 2$ & $1.5110^{5}$ & $18.00 \times 10^{-9}$ & 0.88 & $4.5 \times 10^{5}$ & $8.7710^{-8}$ & 0.65 & $3.12 \times 10^{9}$ & $8.3710^{-6}$ & 0.70 \\
\hline
\end{tabular}




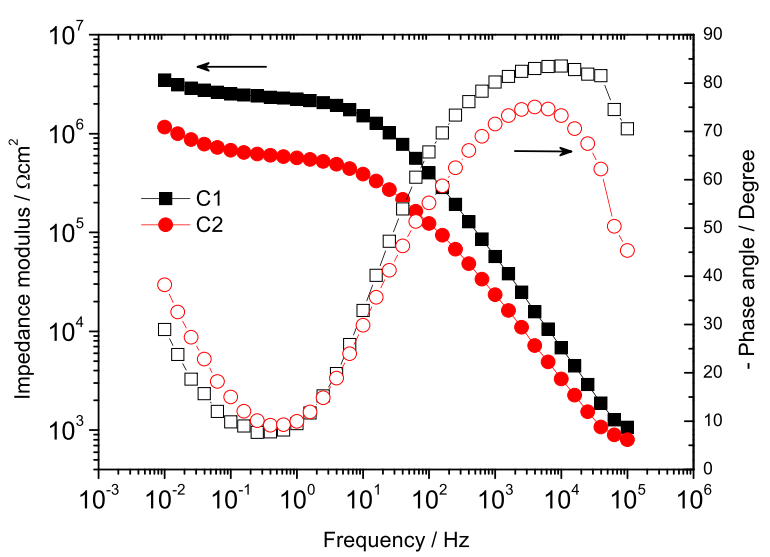

Fig. 7. Impedance and phase angle plots collected in $0.3 \mathrm{wt} . \% \mathrm{Na} 2 \mathrm{SO} 4$ solution for samples $\mathrm{C} 1$ and $\mathrm{C} 2$ before the abrasion cycles.

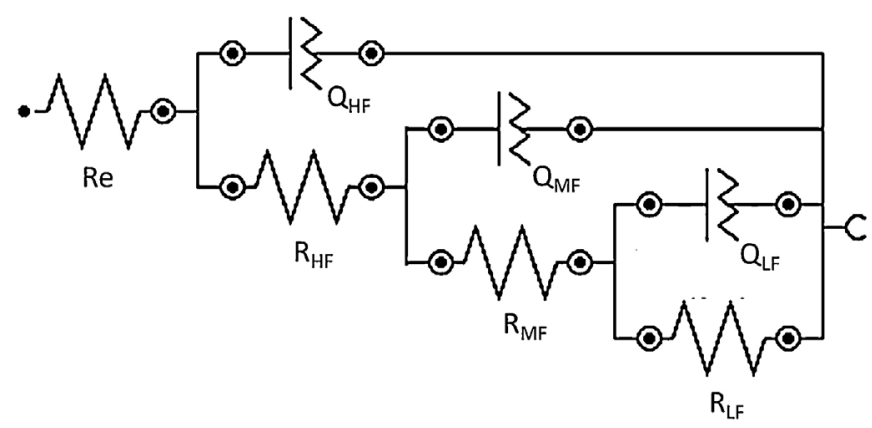

Fig. 8. Electrical equivalent circuit employed for numerical fitting of the experimental spectra.

ing is higher for the thinner sample, compared to the thicker one. As previously anticipated, this fact might rely on the presence of preferential pathways (cracks/pores) in C2 coating in which the electrolyte can permeate. As far as the thickness of C1 and C2 coatings is concerned, (around 5 and $10 \mu \mathrm{m}$, respectively) it is expected to find a lower capacitance value for the thicker sol-gel layer. However, it should be noted that the constant phase element $\left(\mathrm{Q}_{H F}\right)$ for sample C2 is about four times higher compared to C1. Even if the high frequency CPE exploited for the numerical fitting do not correspond to a pure capacitance (exponent " $\alpha$ " is around 0.88-0.94), the increase in pre-factor $\mathrm{Q}_{\mathrm{HF}}$ can be related to a higher amount of water in the coating, in accordance with the simultaneous decrease in $\mathrm{R}_{\mathrm{HF}}$.

Considering the middle and low frequency relaxation processes, the exponent " $\alpha$ " values (equal to $0.56-0.65$ and $0.70-0.74$, respectively) related to the CPEs exploited for the numerical fitting do not permit any clear interpretation of the corresponding prefactors. The values of the $\mathrm{R}_{\mathrm{LF}}$ suggest that the electrolyte reached the metal substrate and corrosion processes are occurring at the metal/solution interface. The higher values obtained for the $\mathrm{C} 1$ coating $\left(3.12 \times 10^{9} \Omega \mathrm{cm}^{2}\right)$ compared to $\mathrm{C} 2\left(1.43 \times 10^{9} \Omega \mathrm{cm}^{2}\right)$ further suggest that before the Taber cycles the thinner coating is more protective compared to the thicker one.

Considering the effect of the abrasion wheels during Taber cycles, notice that after 100 cycles of abrasion (Fig. 6), the mechanical degradation and subsequent penetration of the electrolyte through the coatings lead to the reduction of the protective properties. Indeed, impedance modulus values of the systems decreased from about one decade to $10^{5} \mathrm{ohm} \mathrm{cm}^{2}$. Despite differences in the coating thickness, low frequency impedance modulus values remain comparable up to 1000 abrasion cycles (Fig. 6). However after 1000 cycles, very slight differences of the anticorrosion prop- erties of the two coatings are observed, which can be explained by the microstructural observations. Fig. 3a and d shows the differences in thickness between both coatings $30 \mathrm{ZrO}_{2}$ and $40 \mathrm{ZrO}_{2}$ with values less than $2 \mu \mathrm{m}$ and $3-4 \mu \mathrm{m}$, respectively. It is worth noting that the coating containing $40 \%$ of zirconia particles maintains a higher impedance modulus compared to the coating containing $30 \%$ of zirconia particles. In the case of the latter, the thinnest layer constitutes a faster pathway for the electrolyte to penetrate to the substrate. After increasing the number of cycles (Fig. 6), the total impedance remained constant at a relatively low frequency, showing the protective properties of the coatings which limit corrosion propagation. Better wear resistant properties are therefore expected for the sample containing the higher number of particles.

The effect of mechanical degradation and absorption of liquid onto the coating is even more remarkable considering the phase angle diagram (Fig. 6). For the sample with $40 \%$ of zirconia particles the high frequency time constant decreases in intensity and the second time in the middle frequency range becomes more prominent after 100 and 1000 cycles. The relaxation process in the low frequency range is still observable. However the experimental data scatters below $10^{\circ} \mathrm{Hz}$ and a clear interpretation is therefore complicated.

In fact, as the abrasion created localized defects on the coating, it proved difficult to separate the contribution of both damaged and undamaged areas in the EIS response. The authors attempted to fit the experimental spectra of the damaged coatings by means of the previously described circuit. However, a consistent mathematical modelling of the experimental curves was not possible due to the scattering data in the low frequency range. This is probably related to the effect of mechanical damage which produces a not uniform surface with high roughness, scratches, thickness differences on the Taber tracks promoted by the abrasion action of the wheels. For this reason it was not possible to obtain a satisfactory numerical fitting of the EIS spectra collected over the damaged surfaces.

Generally speaking, the effect of the abrasion promotes the formation of localized defects of the coatings, a thickness reduction and consequent increase of water and ions permeability with the number of abrasion cycles. Figs. $3 \mathrm{c}$ and $4 \mathrm{a}$ illustrate the presence and the morphology of the defects and explain the different corrosion protective behaviors of the coatings. Moreover, in Fig. 4c, the SEM micrograph shows that the outer coating is totally removed and does not play the role of anti-wear coating anymore. On the other hand, in agreement with Fig. 5, the compacted layer of the 40 wt.\% zirconia loaded coating permits higher electrochemical values to be obtained and thus increase the durability of the protective hybrid coating. Indeed, after 1000 abrasion cycles, despite the appearance of a second time constant in the middle frequency, the $40 \mathrm{wt}$.\% zirconia particles coating seems to maintain a certain barrier effect against water and ions permeation.

\section{Conclusions}

In this work we have demonstrated that the sol-gel technology offers the possibility to synthesize innovative architectured systems for anticorrosion and wear properties. Promising anticorrosion coatings have been deposited on a highly corrosion sensitive and uneven mild steel substrate. The architecture is based on alumino-silicated hybrid coatings containing zirconia nanoparticles in the outer layer, well-adapted to the aimed properties. Abrasion test conditions undertaken in this work appeared welladjusted to such thin coatings with a thickness lower than $10 \mu \mathrm{m}$. As the damage produced by the abrasive wheels was rather a thinning of the coating, estimation of the damage level of the samples was thus carried out through microstructural observations and electrochemical measurements. The loss of corrosion protection of 
the lower zirconia loaded coating was attributed to the formation of localized defects after the removal of material. On the contrary, the higher zirconia loaded coating demonstrated an interesting corrosion and wear behavior with the formation of a compacted layer at the top of the outer layer providing a barrier effect against water and ions permeation. Further mechanical characterizations could provide additional information about the hardness of this outer layer.

What is of interest is the successful combination of wear tests and EIS to evaluate the influence of abrasive wear on anticorrosion properties on such thin hybrid sol-gel coatings.

\section{Acknowledgments}

The authors would like to thank Stephane LE BLOND DU PLOUY (UMSCastaing) for SEM and EDS characterizations. This work was performed in the framework of a joint laboratory, called CETIMAT, where CIRIMAT and CETIM collaborate for some aspects of their research.

\section{Appendix A. Supplementary data}

Supplementary data associated with this article can be found, in the online version, at http://dx.doi.org/10.1016/j.porgcoat.2016. 06.015 .

\section{References}

[1] S. Rossi, F. Deflorian, L. Fontanari, A. Cambruzzi, P.L. Bonora, Prog. Org. Coat. 52 (2005) 288-297.

[2] S. Rossi, F. Deflorian, M. Risatti, Surf. Coat. Technol. 201 (2006) 1173-1179.

[3] A. Cambruzzi, S. Rossi, F. Deflorian, Wear 258 (2005) 1696-1705.

[4] M.F. Montemor, Surf. Coat. Technol. 258 (2014) 17-37.

[5] S. Ahmad, A.P. Gupta, E. Sharmin, M. Alam, S.K. Pandey, Prog. Org. Coat. 54 (2005) 248-255.

[6] M. Qian, A.M. Soutar, X.H. Tan, X.T. Zeng, S.L. Wijesinghe, Thin Solid Films 517 (2009) 5237-5242.
[7] I. Díaz, B. Chico, D. de la Fuente, J. Simancas, J.M. Vega, M. Morcillo, Prog. Org. Coat. 69 (2010) 278-286.

[8] B.N. Grgur, M.M. Gvozdenović, V.B. Mišković-Stanković, Z. Kačarević-Popović, Prog. Org. Coat. 56 (2006) 214-219.

[9] P. Balan, M.J. Shelton, D.O.L. Ching, G.C. Hand, L.K. Palniandye, Procedia Mater. Sci. 6 (2014) 244-248.

[10] J.-B. Cambon, J. Esteban, F. Ansart, J.-P. Bonino, V. Turq, S.H. Santagneli, C.V. Santilli, S.H. Pulcinelli, Mater. Res. Bull. 47 (2012) 3170-3176.

[11] A. Pepe, M. Aparicio, S. Cereí, A. Duraín, Mater. Lett. 59 (2005) 3937-3940.

[12] T.T.X. Hang, T.A. Truc, M.-G. Olivier, C. Vandermiers, N. Guerit, N. Pebere, Prog. Org. Coat. 69 (2010) 410-416.

[13] R. Akid, H. Wang, Corros. Sci. 50 (2008) 1142-1148.

[14] P. Balan, A. Ng, C.B. Siang, R.K. Singh Raman, C.E. Seng, Adv. Mater. Res. 686 (2013) 244-249.

[15] G. Tsaneva, V. Kozhukharov, S. Kozhukharov, M. Ivanova, J. Gerwann, M. Schem, T. Schmidt, J. Univ. Chem. Technol. Metal. 43 (2) (2008) 231-238.

[16] P. Kiruthika, R. Subasri, A. Jyothirmayi, K. Sarvani, N.Y. Hebalkar, Surf. Coat. Technol. 204 (2010) 1270-1276.

[17] S. Turri, L. Torlaj, F. Piccinini, M. Levi, J. Appl. Polym. Sci. 118 (2010) 1720-1727.

[18] Alka Phanasgaonkar, V.S. Raja, Surf. Coat. Technol. 203 (2009) 2260-2271.

[19] M. Grundwürmer, O. Nuyken, M. Meyer, J. Wehr, N. Schupp, Wear 263 (2007) 318-329.

[20] C. Li, K. Jordens, G.L. Wilkes, Wear 242 (2000) 152-159.

[21] Standard ASTM D 4060-95, vol. 06.01, American Society for Testing and Materials, Philadelphia, US, 1995.

[22] I. Santana, A. Pepe, E. Jimenez-Pique, S. Pellice, S. Ceré, Surf. Coat. Technol. 236 (2013) 476-484

[23] S. Rahoui, V. Turq, J.-P. Bonino, Surf. Coat. Technol. 235 (2013) 15-23.

[24] M.L. Zheludkevich, R. Serra, M.F. Montemor, K.A. Yasakau, I.M. Miranda Salvado, M.G.S. Ferreira, Electrochim. Acta 51 (2) (2005) 208-217.

[25] K.A. Yasakau, M.L. Zheludkevich, O.V. Karavai, M.G.S. Ferreira, Prog. Org. Coat. 63 (3) (2008) 352-361.

[26] C. Lavollée, M. Gressier, M.-J. Menu, J. Garcia, J.-M. Sobrino, Euro Hybrid Materials and Structures, 92, PFH - Private University of Applied Sciences, 2014.

[27] E. Certhoux, F. Ansart, V. Turq, J.P. Bonino, J.M. Sobrino, J. Garcia, J. Reby, Prog. Org. Coat. 76 (2013) 165-172.

[28] Y. Reyes-Mercado, S. Rossi, F. Deflorian, M. Fedel, Wear 265 (2008) 1820-1825.

[29] A.G. Kannan, N.R. Choudhury, N.K. Dutta, J. Electroanal. Chem. 641 (2010) 28-34.

[30] B. Chico, J.C. Galván, D. de la Fuente, M. Morcillo, Prog. Org. Coat. 60 (2007) 45-53. 